\title{
Potential association between trematode infections and development of pregnancy toxaemia in sheep
}

\author{
E. PAPADOPOULOS ${ }^{1}$, V. S. MAVROGIANNI ${ }^{2}$, A. MITSOURA ${ }^{2}$, S. PTOCHOS ${ }^{1}$, S. A. SPANOS ${ }^{2}$, \\ G. C. FTHENAKIS ${ }^{2}$
}

\begin{abstract}
${ }^{1}$ Faculty of Veterinary Medicine, Aristotle University of Thessaloniki, 54124 Thessaloniki, Greece, E-mail: eliaspap@vet.auth.gr; ${ }^{2}$ Veterinary Faculty, University of Thessaly, 43100 Karditsa, Greece
\end{abstract}

\section{Summary}

Objective of the work was to study a potential association between trematode infections in pregnant ewes and concentrations $\beta$-hydroxybutyrate, which is a ketone body found in animals with pregnancy toxaemia. After administration of a long-acting nematocide, 80 pregnant sheep, infected with trematodes, were allocated as follows; primigravidae ewes in group P-A remained untreated and in group $\mathrm{P}-\mathrm{B}$ were given netobimin; multigravidae ewes in group $\mathrm{M}-\mathrm{A}$ remained untreated, in group $\mathrm{M}-\mathrm{B}$ were given netobimin and in group $\mathrm{M}-\mathrm{C}$ were given rafoxanide. We collected faecal samples for trematode epg counting and blood samples for measurement of $\beta$-hydroxybutyrate concentrations. Mean faecal epg counts of $D$. dendriticum and $F$. hepatica decreased significantly after netobimin administration; mean faecal epg counts of $F$. hepatica, but not of $D$. dendriticum, decreased significantly after rafoxanide administration. Between P-A and P-B, the difference in mean blood $\beta$-hydroxybutyrate concentrations was significant $(P=0.036)$ immediately after lambing. Between $\mathrm{M}-\mathrm{A}$ or $\mathrm{M}-\mathrm{C}$ and $\mathrm{M}-\mathrm{B}$, it was significant $(P \leq 0.002) 28$ days after trematocide administration and immediately after lambing; between M-A and M-C, no significant difference was evident. Immediately after lambing, mean blood $\beta$-hydroxybutyrate concentration in primiparous/multiparous ewes with Dicrocoelium faecal output $\leq 150$ epg was $0.21 / 0.64 \mathrm{mmol} \mathrm{L}^{-1}$, respectively, and in primiparous/multiparous ewes with Dicrocoelium faecal output $>150$ epg was $0.40 / 0.93 \mathrm{mmol} \mathrm{L}^{-1}$, respectively $(P=$ $0.704 /<0.001$, respectively). Mean blood $\beta$-hydroxybutyrate concentration in group $\mathrm{P}-\mathrm{C} / \mathrm{M}-\mathrm{C}$ ewes with Fasciola faecal output of $<16 /<30$ epg was $0.47 / 0.68 \mathrm{mmol} \mathrm{L}^{-1}$, respectively; that in group P-C/M-C ewes with Fasciola faecal output of $\geq 16 / \geq 30$ epg was $0.56 / 0.85 \mathrm{mmol} \mathrm{L}^{-1}$, respectively $(P=0.620 / 0.278$, respectively). The results indicate that more trematode-infected adult ewes were found to have increased $\beta$-hydroxybutyrate blood concentrations and point out to a potential role of liver trematode infections in predisposing adult ewes to pregnancy toxaemia.

Keywords: Dicrocoelium; Fasciola; pregnancy toxaemia; risk factor; sheep; trematode; $\beta$-hydroxybuturate

\section{Introduction}

Pregnancy toxaemia is the most important metabolic disease of pregnant ewes, caused by abnormal metabolism of carbohydrates and fats, during the final stage of pregnancy (Brozos et al., 2011). The disease is a significant cause of peri-parturient deaths in sheep (Mavrogianni \& Brozos, 2008). Various factors have been identified to predispose ewes to the disease. Decreased availability of nutrients, in association with the increased requirements of the animals during gestation, leads to development of the pathological condition.

Pathogenesis of the disease involves depletion of the liver glycogen reserves, mobilisation of the fatty deposits for use as energy source and accumulation of triglycerides into hepatocytes, resulting to development of fatty liver and formation of ketone bodies (Radostits et al., 2007; Sargison, 2007). Increased gluconeogenesis during the final stage of pregnancy inhibits incorporation of acetyl coenzyme A into the Krebs cycle and leads to accumulation of triglycerids into the hepatic cells. This way, the acetyl coenzyme $\mathrm{A}$ is transformed to acetate, $\beta$-hydroxubutyrate and acetone. Accumulation of triglycerides within the liver leads to hepatic dysfunction, which further aggravates production of ketone bodies and more accumulation of triglycerides as parts of a vicious circle (Bobe et al., 2004; Sargison, 2007; Musso et al., 2009).

A salient paraclinical finding of the disease is hyperketonaemia of affected animals. The main ketone body found in blood of pregnant sheep is $\beta$-hydroxyburate; its concentration can be used to detect animals at risk to develop 
pregnancy toxaemia. If the number of foetuses carried has not been identified, the value of $0.8 \mathrm{mmol} \mathrm{L}^{-1}$ should be considered to distinguish animals at risk to develop the disorder. Otherwise, if the number of foetuses carried had been determined, then $\beta$-hydroxybutyrate concentration should be measured only in the blood of animals carrying multiple foetuses; in this case, the cut-off value to be used for identifying animals at risk is $1.1 \mathrm{mmoL} \mathrm{L}^{-1}$ (Sargison 1995, 2007; Braun et al., 2010; Brozos et al., 2011).

Objective of the work was to study a potential association between trematode infections in pregnant ewes and concentrations $\beta$-hydroxybutyrate. This would suggest a potential association between trematode infections and pregnancy toxaemia.

\section{Materials and methods}

\section{Study design and animals}

The study was performed in a dairy flock in Central Greece. At the beginning of the autumn (D -134) prior to the main study, 152 Lacaune-breed, female sheep in the flock were exposed to the 'ram effect', in order to achieve some degree of synchronisation of oestrous cycles. Then, rams of confirmed fertility were introduced into the females (ram:ewe ratio $=1: 15)$ on the 1 st October $(D-104)$, for lambings to take place in the subsequent spring.

Animals for inclusion in the study were chosen at the end of November (D -46), among those that had been mated, but had not returned to oestrus. At the end, 30 primigravidae (P) and 50 multigravidae (M) ewes were selected for inclusion in the study and, on the same day, were drenched with moxidectin (CYDECTIN, Pfizer Animal Health; dose rate: $0.2 \mathrm{mg} \mathrm{kg}^{-1}$ bodyweight).

On the 13th January (D 0), i.e. at around $3-3.5$ months of pregnancy, the 80 animals were drenched again with moxidectin. Then, they were allocated into five groups and treated as follows; primigravidae ewes in group P-A $(\mathrm{n}=$ 15) remained untreated; primigravidae ewes in group $P-B$ $(\mathrm{n}=15)$ were drenched with netobimin (HAPADEX or. dr., Intervet-Schering-Plough, Boxmeer, The Netherlands; dose rate: $20 \mathrm{mg} \mathrm{kg}^{-1}$ bodyweight); multigravidae ewes in group M-A $(\mathrm{n}=15)$ remained untreated; multigravidae ewes in group M-B $(\mathrm{n}=15)$ were drenched with netobimin (dose rate: $20 \mathrm{mg} \mathrm{kg}^{-1}$ bodyweight; multigravidae ewes in group $\mathrm{M}-\mathrm{C}(\mathrm{n}=20)$ were given rafoxanide (RAFOXANIDE tabs, Provet Animal Health, Alimos, Greece; dose rate: $7.5 \mathrm{mg} \mathrm{kg}^{-1}$ bodyweight).

Animals were maintained in a semi-intensive system, grazing in private paddocks during the day and kept indoors during the night. They were also given commercial compound feed, $0.7 \mathrm{~kg}$ per animal daily, increased to 1.0 $\mathrm{kg}$ per animal daily subsequently to D 20 (i.e., at around $3.5-4$ months of pregnancy). Good quality hay was also provided ad libitum.

As part of planned health program, dogs in the flock had been given anthelmintics (including praziquantel) at regular intervals for the last three years before start of the study. Moreover, monitoring of routinely-slaughtered animals had not, for many months, revealed evidence of parasitic cystic formations in the liver of the flock's sheep.

\section{Samplings and examinations}

Faecal samples from all 152 females in the initial batch were first collected on D -134, in September before start of the mating period; samples were again collected on D -63 , in mid-November. Thereafter, samples were collected only from the 80 animals into the study, on D -31 (mid-December), on D 0 (mid-January), on D 28 (mid-February), on D 41 - D 57(within 1 day after lambing of each animal) and on D 97 (40 to 57 days after lambing of each animal).

Faecal samples were collected directly from the rectum of each animal, placed into an isothermic box and transferred to the laboratory for epg counting. Each sample was divided in three lots, as follows. One lot was processed for trichostrongylid epg counting according to the modified McMaster technique with saturated $\mathrm{NaCl}$ solution; the second lot was processed for Dicrocoelium dendriticum epg counting according to the modified McMaster technique with $\mathrm{ZnSO}_{4}$ (sp.g. 1.40); finally, the third lot was processed for Fasciola spp. and Paramphistomum cervi epg counting by using the Telemann sedimentation technique (acid - ether) (Ministry of Agriculture, Fisheries and Food, 1986; Rehbein et al., 1999; Otranto \& Traversa, 2002; Taylor, 2010).

On D 0 (mid-January), on D 28 (mid-February) and on D 41 - D 57 (immediately post-partum), a blood sample was collected from each ewe in the study, for measurement of $\beta$-hydroxybutyrate concentration. In all the occasions, samples were collected $6-7 \mathrm{~h}$ after the morning feeding of the animals. A drop of blood was placed on a strip, which was subsequently inserted into an automated reader (Precision Xceed Meter; Abbott Laboratories, Abbott Park, IL, USA), validated for measurement of $\beta$-hydroxybutyrate concentration in sheep blood (Panousis et al., 2012).

\section{Data management and analysis}

The arithmetic mean of epg counts (AM) was calculated as $A M=\left(\right.$ count $_{1}+$ count $_{2}+\ldots+$ count $\left._{\mathrm{n}}\right) / n$, where $n$ is the number of animals in the group. Results for samplings performed on D -134 and D -63 took into account epg counts only the 80 animals into the study. Analysis of covariance for post-treatment results, using pre-treatment counts as covariate and treatment as fixed effect, was performed in order to compare differences in epg counts between the two groups of primigravidae/primiparous ewes and the three groups of multigravidae/multiparous ewes. The method was applied for Dicrocoelium and Fasciola epg counts separately. Analysis of covariance was employed for comparison of results of blood $\beta$-hydroxybutyrate concentration, using value on $\mathrm{D} 0$ as covariate and treatment as fixed effect.

Based on the D 41 - D 57 (immediately post-partum) results, the following comparisons were made: (a) $\beta$-hydroxybutyrate blood concentration of ewes with Dicrocoelium faecal output of $\leq 150$ or $>150$ epg and (b) $\beta$-hydroxybutyrate blood concentration of group P-A or group 


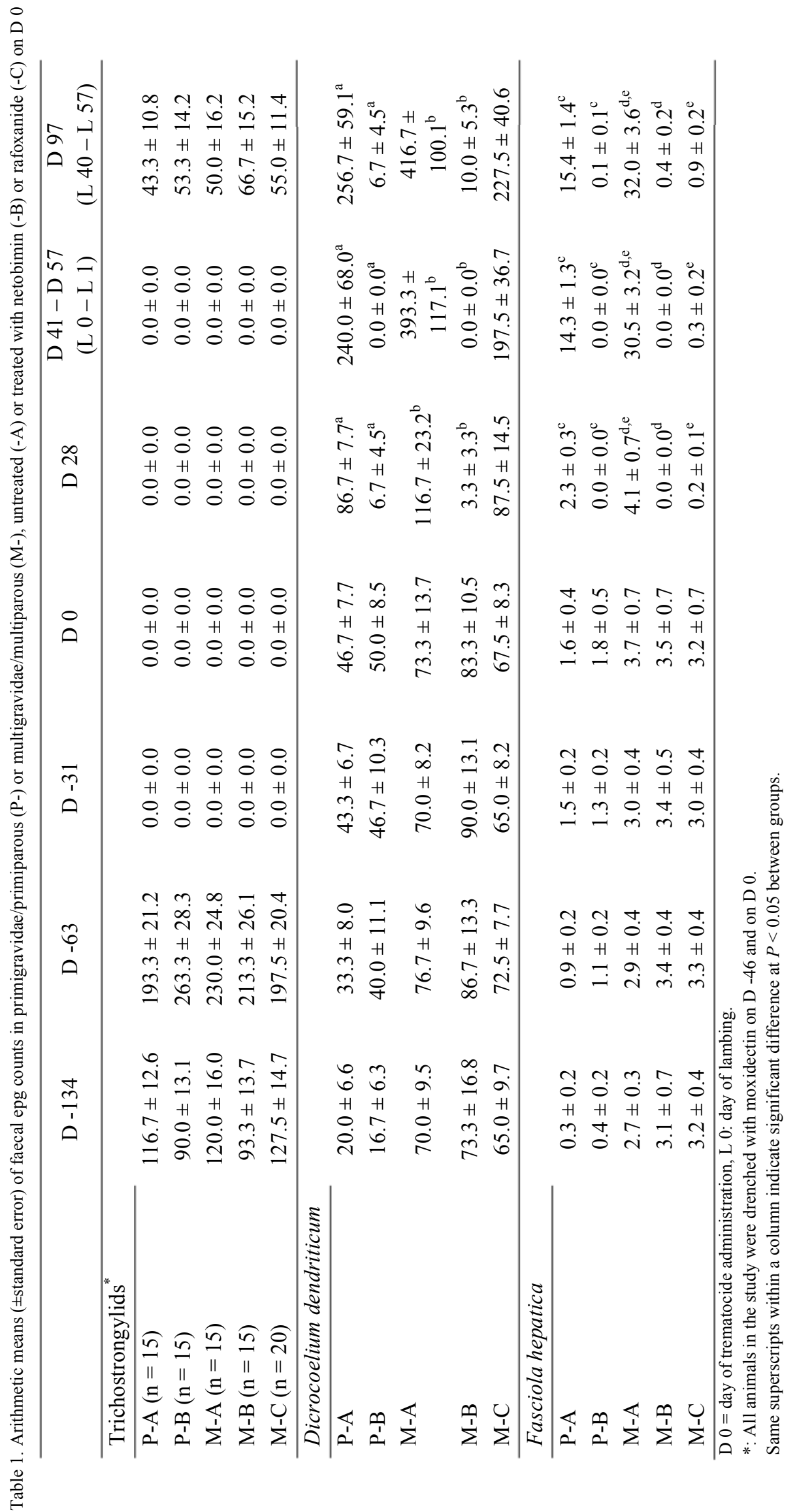


M-A ewes with Fasciola faecal output of $<16$ or $\geq 16$ epg (P-A ewes) or $<30$ or $\geq 30$ epg (M-A ewes). The t-test was used for the above comparisons.

Separate analyses were performed for primigravidae/primiparous ewes and multigravidae/multiparous ewes. Level of significance was set at $P=0.05$.

\section{Results}

\section{Clinical findings during pregnancy and at parturition}

During pregnancy and at lambing, no cases of clinical disease or obstetrical problems were recorded in any ewe in the study. All animals lambed normally. 'Total lambs born per ewe' (number of liveborn and stillborn lambs / number of ewes that lambed) in each group was as follows: $\mathrm{P}-\mathrm{A}=$ $1.40, \mathrm{P}-\mathrm{B}=1.53, \mathrm{M}-\mathrm{A}=2.00, \mathrm{M}-\mathrm{B}=2.00, \mathrm{M}-\mathrm{C}=1.90$.

\section{Parasitological findings}

Initially, trichostrongylid eggs were found in faecal samples from all animals. Consequently to moxidectin administration, trichostrongylid epg counts were 0.0 until immediately post-partum; they increased again on D 97.

Before start of the study, all animals were naturally infected with trematodes (D. dendriticum and/or $F$. hepati$c a$ ). On D 0, mean ( \pm standard error of the mean) faecal epg counts of trematodes in samples from multigravidae ewes $(D$. dendriticum: $74.0 \pm 5.6, F$. hepatica: $3.4 \pm 0.3)$ were significantly higher than those in samples from primigravidae ewes $(D$. dendriticum: $48.3 \pm 6.1, F$. hepati$c a: 1.7 \pm 0.4)(P<0.002)$. Before treatment, differences between $\mathrm{P}-\mathrm{A}$ and $\mathrm{P}-\mathrm{B}$ and between $\mathrm{M}-\mathrm{A}, \mathrm{M}-\mathrm{B}$ and $\mathrm{M}-\mathrm{C}$ were not significant $(P>0.33)$.

Among primigravidae ewes, mean faecal epg counts of $D$. dendriticum and $F$. hepatica decreased significantly $(P<$ 0.001 ) after netobimin administration (group P-B) and, in all sampling occasions, were $\leq 7.0$. Differences between the two groups were significant for both parasites $(P<0.001)$. Among multigravidae ewes, mean faecal epg counts of $D$. dendriticum decreased significantly $(P<0.001)$ after netobimin (M-B ewes), but not rafoxanide (M-C ewes), administration; in all sampling occasions from M-B ewes, they were $\leq 10.0$. Mean faecal epg counts of $F$. hepatica decreased significantly $(P \leq 0.001)$ after netobimin $(\mathrm{M}-\mathrm{B}$ ewes) or rafoxanide administration (M-C ewes); in all sampling occasions from $\mathrm{M}-\mathrm{B}$ or $\mathrm{M}-\mathrm{C}$ ewes, they were
$<1.0$. Differences between the three groups were significant for $F$. hepatica $(P<0.01)$, whilst differences for $D$. dendriticum were significant only between $\mathrm{M}-\mathrm{A}$ and $\mathrm{M}-\mathrm{B}$ $(P<0.001)$.

In no case, $P$. cervi eggs were observed. Detailed parasitological results are in Table 1.

\section{Blood $\beta$-hydroxybutyrate concentrations}

Among primigravidae ewes, there were no significant differences in mean blood $\beta$-hydroxybutyrate concentrations between P-A and P-B on D 0 and D $28(P>0.20)$; on $\mathrm{L} 0-\mathrm{L} 1$, the difference in mean blood $\beta$-hydroxybutyrate concentrations between P-A $\left(0.49 \mathrm{mmol} \mathrm{L}^{-1}\right)$ and P-B $(0.36$ mmol L $\left.{ }^{-1}\right)$ was significant $(P=0.036)$. Incidence of ewes with blood $\beta$-hydroxybuturate concentration $\geq 1.1 \mathrm{mmol} \mathrm{L}^{-1}$ was 0.069 for P-A and 0.0 for P-B group.

Among multigravidae ewes, there were no significant differences in mean blood $\beta$-hydroxybutyrate concentrations on D $0(P>0.23)$; later however, differences in mean blood $\beta$-hydroxybutyrate concentrations between M-A (on D 28: $0.72 \mathrm{mmol} \mathrm{L}^{-1}$, on D 41 - D 57 [immediately postpartum]: $0.75 \mathrm{mmol} \mathrm{L}^{-1}$ ) or M-C (on D 28: $0.71 \mathrm{mmol} \mathrm{L}^{-1}$, on D 41 - D 57 [immediately post-partum]: $0.77 \mathrm{mmol} \mathrm{L}^{-}$ ${ }^{1}$ ) and M-B (on D 28: $0.35 \mathrm{mmol} \mathrm{L}^{-1}$, on D 41 - D 57 [immediately post-partum]: $0.45 \mathrm{mmol} \mathrm{L}^{-1}$ ) were significant $(P \leq 0.002)$, whilst those between M-A and M-C were not $(P>0.38)$. Incidence of ewes with blood $\beta$-hydroxybuturate concentration $\geq 1.1 \mathrm{mmol} \mathrm{L}^{-1}$ was 0.222 in $\mathrm{M}-\mathrm{A}$ ewes, 0.069 in $\mathrm{M}-\mathrm{B}$ ewes and 0.133 in $\mathrm{M}-\mathrm{C}$ ewes. Detailed results of measurements of $\beta$-hydroxybutyrate concentrations are in Table 2.

On D 41 - D 57 (immediately post-partum), mean blood $\beta$ hydroxybutyrate concentration in primiparous ewes with Dicrocoelium faecal output of $\leq 150$ epg was $0.21 \pm 0.0$ mmol L ${ }^{-1}$; that in primiparous ewes with Dicrocoelium faecal output of $>150$ epg was $0.40 \pm 0.1 \mathrm{mmol} \mathrm{L}^{-1}(P=$ $0.704)$. On the same sampling occasion, mean blood $\beta$ hydroxybutyrate concentration in multiparous ewes with Dicrocoelium faecal output of $\leq 150$ epg was $0.64 \pm 0.0$ mmol L ${ }^{-1}$; that in multiparous ewes with Dicrocoelium faecal output of $>150$ epg was $0.93 \pm 0.1 \mathrm{mmol} \mathrm{L}^{-1}(P<$ $0.001)$. Mean blood $\beta$-hydroxybutyrate concentration in group P-C ewes with Fasciola faecal output of $<16$ epg was $0.47 \pm 0.0 \mathrm{mmol} \mathrm{L}^{-1}$; that in group $\mathrm{P}-\mathrm{C}$ ewes with Fasciola faecal output of $\geq 16$ epg was $0.56 \pm 0.1 \mathrm{mmol} \mathrm{L}^{-1}$

Table 2. Results of $\beta$-hydroxybuturate blood concentrations (mean \pm standard error, $\mathrm{mmol} \mathrm{L}^{-1}$ ) in primigravidae/primiparous ( $\mathrm{P}-$ ) or multigravidae/multiparous (M-), untreated (-A) or treated with netobimin (-B) or rafoxanide (-C) on D 0

\begin{tabular}{lccc}
\hline & D 0 & D 28 & $\begin{array}{c}\text { D 41 - D 57 } \\
(\text { L 0 - L 1) }\end{array}$ \\
\hline P-A & $0.25 \pm 0.0$ & $0.21 \pm 0.0$ & $0.49 \pm 0.1^{\mathrm{a}}$ \\
P-B & $0.25 \pm 0.0$ & $0.23 \pm 0.0$ & $0.36 \pm 0.0^{\mathrm{a}}$ \\
M-A & $0.51 \pm 0.1$ & $0.72 \pm 0.0^{\mathrm{a}}$ & $0.75 \pm 0.1^{\mathrm{b}}$ \\
M-B & $0.57 \pm 0.0$ & $0.35 \pm 0.1^{\mathrm{a}, \mathrm{b}}$ & $0.45 \pm 0.1^{\mathrm{b}, \mathrm{c}}$ \\
M-C & $0.53 \pm 0.0$ & $0.71 \pm 0.1^{\mathrm{b}}$ & $0.77 \pm 0.1^{\mathrm{c}}$ \\
\hline
\end{tabular}

D $0=$ day of trematocide administration, L $0=$ day of lambing.

Same superscripts within a column indicate significant difference at $P<0.05$ between groups. 
$(P=0.620)$. Mean blood $\beta$-hydroxybutyrate concentration in group M-C ewes with Fasciola faecal output of $<30$ epg was $0.68 \pm 0.1 \mathrm{mmol} \mathrm{L}^{-1}$; that in group $\mathrm{M}-\mathrm{C}$ ewes with Fasciola faecal output of $\geq 30$ epg was $0.85 \pm 0.1 \mathrm{mmol} \mathrm{L}^{-1}$ $(P=0.278)$.

\section{Discussion}

The experimental approach allowed investigation of a potential role for trematode parasites only. After administration of moxidectin, which is licenced with a persistent efficacy against nematodes, animals in the study remained free from those parasites, as confirmed by absence of trichostrongylid eggs in faecal samples during late stages of pregnancy; hence, any possible adverse effects by these parasites were excluded. Use of animals with no flukicide administration allowed the evaluation of potential effects of trematodes. Administration of netobimin, which is licenced against $F$. hepatica and $D$. dendriticum helminthes, provided animals free from trematodes. Administration of rafoxanide, which is a selective fasciolocide, allowed evaluation of the potential role of $D$. dendriticum, which is of importance for the sheep industry in South European countries (Greece: Sotiraki et al., 1999; Italy: Otranto \& Traversa, 2002; Spain: Ferre et al., 1994).

The results of the final sampling, 97 days after administration of netobimin or rafoxanide, reflected the presence of small numbers of immature forms of the parasites ('young flukes') in the liver during the final stage of pregnancy (D 41 - D 57); these did not produce eggs, which would have allowed coprological diagnosis at that time, but would still have been able to cause liver damage and to impair liver function (Taylor et al., 2007). As young flukes need long time to start producing eggs, a sampling over one month after lambing was necessary to confirm infection with only small numbers of young flukes. Flukicides are, at least partly, effective against young flukes (Benchaoui \& McKellar, 1993), hence reduction of their numbers during pregnancy was of further benefit to the animals. Alternatively, one may suggest that the anthelmintic drugs administered temporarily suppressed egg shedding by adult trematode parasites, but did not kill them all.

Although, no animal developed clinical pregnancy toxaemia, significantly more trematode-infected adult ewes (mixed $F$. hepatica plus $D$. dendriticum infection or sole $D$. dendriticum infection) were found to be at risk to develop the disorder, than treated animals. The results point out to a potential role of liver trematode infections in predisposing adult ewes to pregnancy toxaemia.

Various lesions can be caused by trematodes in the liver of affected sheep. In $F$. hepatica infections, cholangiohepatitis, hepatocyte degeneration, micro-abscessation, coagulative necrosis, extensive fibrosis and loss of hepatic parenchyma have been identified (Meeusen et al., 1995; Rushton \& Murray, 1997; Kumar, 1999; Simsek et al., 2011). In D. dendriticum infections, hepatocyte damage, cholangitis - cholangiectasia (in the interlobular bile ducts as well), cirrhosis and fibrosis can be present (Jithendran \& Bhat,
1996; Kumar, 1999; Manga-González \& González-Lanza, 2005). Moreover, Frank et al. (1984, cited by Manga-González \& González-Lanza, 2005) suggested that toxic metabolites of liver trematodes can damage hepatocytes in the entire liver parenchyma (i.e., not only in parasitised areas of the organ) and be responsible for extensive organ damages. Finally, specifically in $D$. dendriticum infections, histochemical studies have shown marked depletion of hepatocyte glucogen content (Kumar, 1999), leading directly to reduced energy availability for affected animals. Hence, one can suggest that, as liver lesions caused by the trematode helminthes may impede hepatic function, likely the organ cannot address the already increased glyconeogenetic requirements needed during late stages of pregnancy, which is the key mechanism for development of pregnancy toxaemia (Sargison, 2007).

Depressed appetite and, hence, feed intake, present in trematode infections (Taylor et al., 2007), may also contribute and deteriorate the situation. Finally, reduced feed conversion efficiency, reported in trematode infections (Hawkins \& Morris, 1978), may further aggravate the problem. The above, coupled with the liver damage caused by the parasites, lead to increased production of ketone bodies by the liver. This was reflected in the higher concentrations of $\beta$-hydroxyburate in trematode-infected ewes, as well as in the larger number of ewes with $\beta$-hydroxyburate concentration $\geq 1.1 \mathrm{mmol} \mathrm{L}^{-1}$. One may extrapolate that in flocks where various risk factors for pregnancy toxaemia accumulate (e.g., suboptimal feeding), their synergistic effect with trematode infections may lead to clinical cases of pregnancy toxaemia.

$\beta$-hydroxybutyrate blood concentrations recorded in trematode-infected young animals were lower than those in older ewes. One may suggest that absence of extensive or long-standing liver lesions, due to lack of previous trematode infections (given that repeat trematode infection were found to cause more pronounced lesions compared to those developing in primary infections [Meeusen et al., 1995]) allowed the liver of these animals to cover requirements. Additionally, this might reflect the smaller number of foetuses borne by these animals during gestation, which posed smaller energy requirements.

In view of all the above, one may extrapolate that in flocks where many risk factors for pregnancy toxaemia accumulate (e.g., suboptimal feeding), their synergistic predisposing effect, coupled with trematode infection could lead to clinical cases of pregnancy toxaemia. It is noteworthy that trematode infections have been previously found to predispose ewes to other liver disorders, e.g. cholelithiasis (Katsoulos et al. 2011).

Strategic administration of anthelmintics to ewes is important for prevention of development of resistance of parasites to these drugs (Varady et al., 2011). Moreover, administration at specific times during the annual management cycle of sheep is important. For example, administration at the final stage of pregnancy eliminates helminthes (thus, increasing production potential for ewes) and prevents the built-up of parasitic burdens in the envi- 
ronment (Fthenakis et al., 2012). The present results indicate that it can also contribute to prevention of pregnancy toxaemia in ewes, especially if other predisposing factors for the disease are present in a flock.

\section{Acknowledgements}

Mr A. Sfetsios is thanked for consenting in performance of the study in his flock and for active help in successful completion.

\section{References}

Benchaoui, H. A., McKellar, Q. A. (1993): Effect of early treatment with rafoxanide on antipyrine clearance in sheep infected with Fasciola hepatica. Xenobiotica, 23: $439-448$

Bobe, G., Young, J. W., Beitz, D. C. (2004): Pathology, etiology, prevention, and treatment of fatty liver in dairy cows. J. Dairy Sci., 87: 3105 - 3124

Braun, J. P., Trumel, C., Bézille, P. (2010): Clinical biochemistry in sheep: a selected review. Small Rumin Res 92: $10-18$

Brozos, C., Mavrogianni, V. S., Fthenakis, G. C. (2011): Treatment and control of peri-parturient metabolic diseases: pregnancy toxemia, hypocalcemia, hypomagnesemia. Vet. Clin. N. Am. Food Anim. Pract., 27: $105-113$

Ferre, I., OrtegA-MoraA, L. M., Rojo-VÁzQuez, F. A. (1994): Prevalance of Dicrocoelium dendriticum infection in sheep in León province (NW Spain). Prev. Vet. Med., 21: $147-154$

Fthenakis, G. C., Arsenos, G., Brozos, C., Fragkou, I. A., Giadinis, N. D., Giannenas, I., Mavrogianni, V. S., PAPADOPOULOS, E., VALASI, I. (2012): Health management of ewes during pregnancy. Anim. Reprod. Sci., 130: $198-212$

Hawkins, C. D., Morris, R. S. (1978): Depression of productivity in sheep infected with Fasciola hepatica. Vet. Parasitol., 4: 341 - 351

JithendRAn, K. P., Bhat, T. K. (1996): Prevalence of dicrocoeliosis in sheep and goats in Himachal Pradesh, India. Vet. Parasitol., 61: 265 - 271

Katsoulos, P. D., Christodoulopoulos, G., Karatzia, M. A., Pourliotis, K., MinAs, A. (2011): Liver flukes promote cholelithiasis in sheep. Vet. Parasitol., 179: 262 - 265

KumAR V (1999): Trematode Infections and Diseases of Man and Animals. Kluwer, Dordrecht

MANGA-GonZÁlez, M.Y., GonZÁlez-LANZA, C. (2005): Field and experimental studies on Dicrocoelium dendriticum and dicrocoeliasis in northern Spain. J. Helminthol., 79: $291-302$

Mavrogianni, V. S., Brozos, C. (2008): Reflections on the causes and the diagnosis of peri-parturient losses of ewes. Small Rumin. Res., 76: 77 - 82

Meeusen, E., LeE, C. S., Rickard, M. D., Brandon, M. R. (1995): Cellular responses during liver fluke infection in sheep and its evasion by the parasite. Parasite Immunol., 17: $37-45$

Ministry OF AGRICUlture, Fisheries AND FoOd (1986): Manual of Veterinary Parasitological Laboratory Techniques, Reference Book 418. HMSO, London

Musso, G., Gambino, R., Cassade, M. (2009): Recent insights into hepatic lipid metabolism in non-alcoholic fatty liver disease (NAFLD). Prog. Lipid. Res., 48: 1 - 26 Otranto, D., Traversa, D. (2002): A review of dicrocoeliosis of ruminants including recent advances in the diagnosis and treatment. Vet. Parasitol., 107: 317 - 335

Panousis, N., Brozos, C., Karagiannis, I., Giadinis, N. D., LAFI, S., KritsePi-Konstantinou, M. (2012): Evaluation of Precision Xceed ${ }^{\circledR}$ meter for on-site monitoring of blood beta-hydroxybutyric acid and glucose concentrations in dairy sheep. Res. Vet. Sci., 95: $435-439$

Radostits, O. M., GaY, C. C., Hinchcliff, K. W., Constable, P. D. (2007): Veterinary Medicine: A Textbook of the Diseases of Cattle, Horses, Sheep, Pigs and Goats, 10th edn. Saunders, Philadelphia

REHbein, S., KoKotT, S., Lindner, T. (1999): Evaluation of techniques for the enumeration of Dicrocoelium eggs in sheep faeces. J. Vet. Med. A, 46: 133 - 139

Rushton, B., MurRAY, M. (1997): Hepatic pathology of a primary experimental infection of Fasciola hepatica in sheep. J. Comp. Pathol., 87: 459 - 470

SARGiSON, N. D. (1995): Recent advances in the diagnosis, prognosis and treatment of ovine pregnancy toxaemia. In Proceedings of Meetings of the Sheep Veterinary Society, volume 19 , pp. $27-32$

SARGison, N. D. (2007): Pregnancy toxaemia. In: AitKen, I. D. (Ed) Diseases of sheep, 4th edn. Blackwell, Oxford, pp. $359-363$

SimseK, S., Utuk, A. E., BALKAyA, I. (2011): Molecular differentiation of Turkey cattle isolates of Fasciola hepatica and Fasciola gigantica. Helminthologia, 48: 3 - 7

SotiraKi, S. T., LeONTIDES, L. S., Himonas, C. A. (1999): The effect of transportation and confinement stress on egg production by Dicrocoelium dendriticum in sheep. J. Helminthol., 73: 337 - 339

TAYLOR, M. A. (2010): Parasitological examinations in sheep health management. Small Rumin. Res., 92: $120-$ 125

TAYlor, M. A., CoOP, R. L., WALl, R. L. (2007): Veterinary Parasitology, 3rd edn. Blackwell, Oxford

VÁrady, M., PAPAdOPOUlos, E., DolinskÁ, M., KÖNIGOVÁ, A. (2011): Anthelmintic resistance in parasites of small ruminants: sheep versus goats. Helminthologia 48: $137-144$ 